\title{
Nano MMT Modified PMMA Anti-Skid Coating Material Design Mechanism and Mechanical Property Test Yong-Qiang ZHONG
}

Transportation College, Huaiyin Institute of Technology, Huai'an 223003, China

zyqjlu@126.com

Keywords: PMMA, Modified, Nano MMT, Anti-Skid coating material, Component design, Mechanics performance test.

Abstract. For the development of the mechanical properties of better color anti-skid road surface coating material, nano MMT modified agent was added to PMMA material to modify its mechanical property. Various proportional nano MMT modified Polymethylmethacrylate (PMMA) were designed .Then tensile strength tests before and after coating materials nano modified were done by universal testing machine and preparation specimens. The results show that PMMA strength with adding MMT is significantly higher than no additive under different hardening agent ratio. Microscopic mechanism and macroscopic performance show that adding nanometer MMT improved the mechanical properties of PMMA.

\section{Introduction}

Color anti-skid road surface is laid in the original road surface (Fig.1).Color anti-skid road surface is consist of the base course, road surface (asphalt or cement concrete pavement), adhesive layer, color non-slip aggregate protection layer.

Pavement + adhesive coating+ color aggregate is now the most commonly used anti-skid road structure [1]. The laying sequence makes perfect combination of the glue with pavement and color non-slip aggregate. Because colored pavement layer is thinner, the influence of vehicle into the road surface is small [2-3]. It makes driving more smoothly. Coloured aggregate is shown in Fig.2. This paper studies its non-slip coating material.

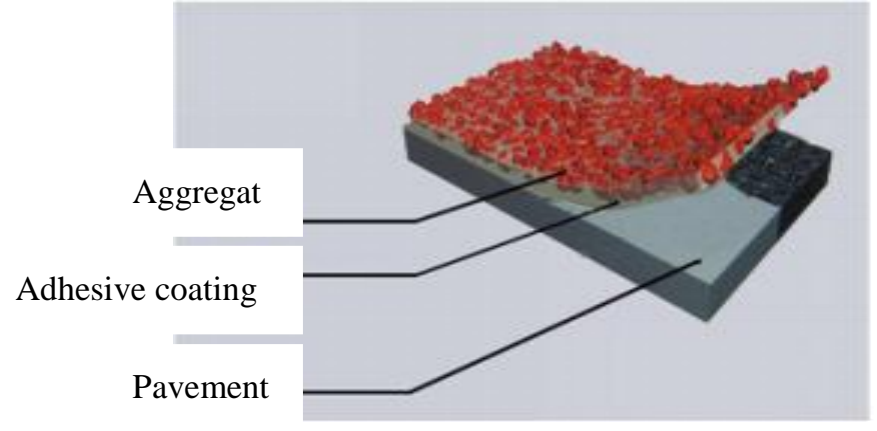

Fig.1 Color anti-skid road surface structure

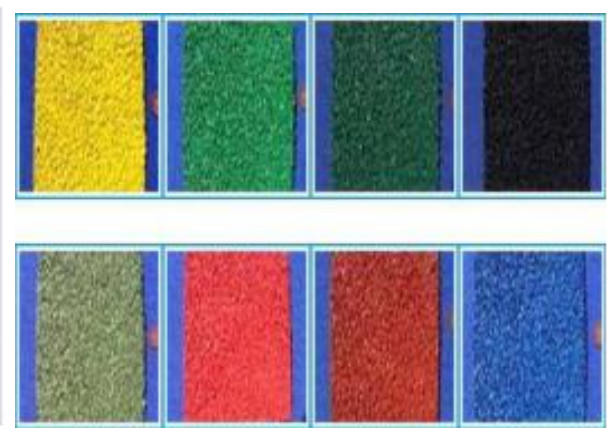

Fig.2 Color aggregate diagram 


\section{Material and Methods}

\section{Material}

Nano MMT Modified PMMA Reaction Mechanism. Polymethylmethacrylate can be abbreviated to PMMA. It is so far the most excellent material quality of synthesis transparent material and the price is cheaper.

PMMA resin is avirulent environmental protection material and a colorless liquid, as shown in Fig.3.Its boiling point is $101{ }^{\circ} \mathrm{C}$ and the density is $0.940 \mathrm{~g} / \mathrm{cm}^{3}$ [4-5].It is the base material of adhesives for color anti-skid road and it has good chemical stability and weather resistance. The shortcoming of PMMA resinis is very brittle cracking, surface strength is low [6]. Its Chemical reaction equation indicated below.

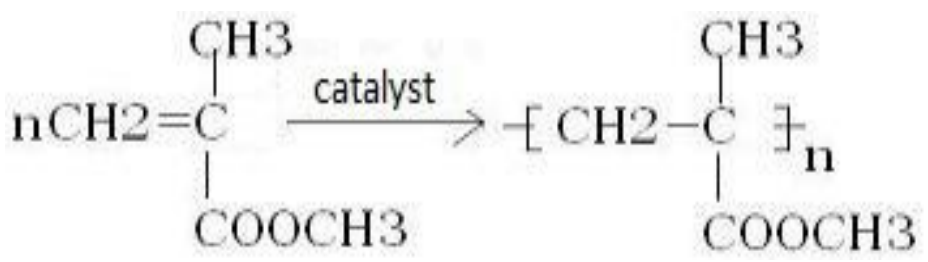

Nano MMT is a natural mineral silicate. The main mineral component is bentonite ore. It can be widely used in the industries of high polymer material as nanometer polymer additives. It can improve the impact resistance, fatigue resistance, dimensional stability and gas barrier properties, etc. Adding nanometer materials MMT to polymethylmethacrylate adhesives can appropriately increase its bonding strength, as shown in Fig. 4[7]. MMT chemical structural formula can be written as: $\mathrm{Na}_{0.7} \mathrm{Al}_{33} \mathrm{Mg}_{0.7} \mathrm{Si}_{8} \mathrm{O}_{20}(\mathrm{OH})_{4} \cdot \mathrm{nH}_{2} \mathrm{O}$. MMT mainly contains $50 \%$ to $70 \% \mathrm{SiO}_{2}, 15 \%$ to $20 \% \mathrm{Al}_{2} \mathrm{O}_{3}$.

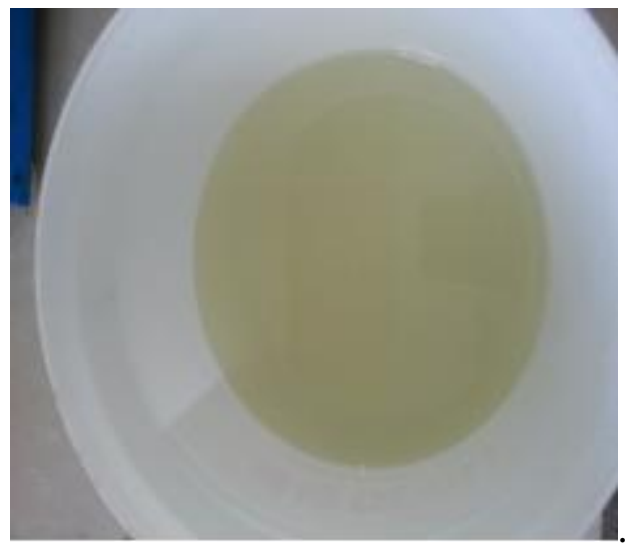

a) Polymethylmethacrylate (PMMA)

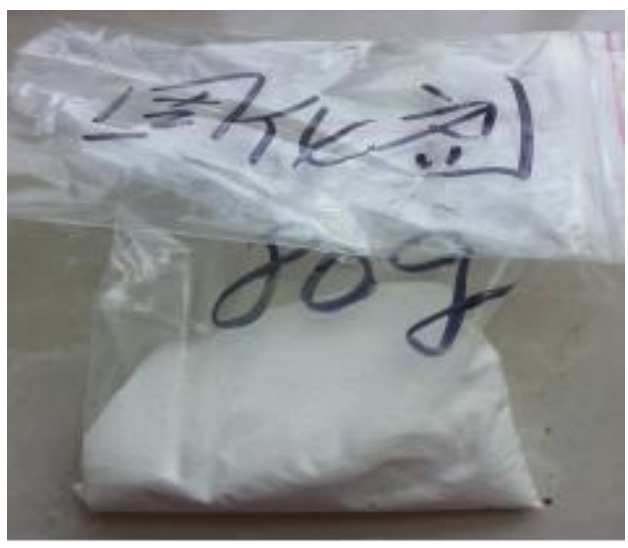

b) Hardening agent

Fig.3 Polymethylmethacrylate and hardening agent material
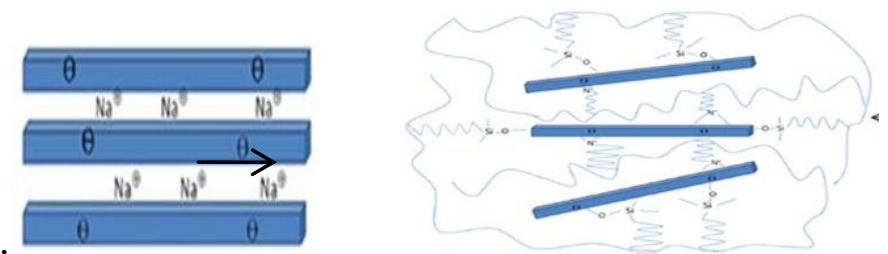

Fig. 4 Reaction scheme of PMMA/reactive montmorillonite nanocomposites. 
Polymer PMMA gets into MMT layers to form intercalated nanocomposites. It will change the polarity between layers of MMT, increase affinity with organic molecules and make layer spacing increases that the organic monomer molecules or polymer molecules insert. Because nano MMT dispersed in the PMMA matrix, it plays a role in a uniformly distributed load and the transmission, transfer, share of the stress and blocking the crack further development. Therefore, the mechanical properties of composite materials will increase to a certain extent with the increase content of MMT. This is principle of modification of PMMA by nano MMT.

Two-component Nano Modified Polymethylmethacrylate (PMMA) Adhesive Materials Design. Polymethylmethacrylate binder is a two-component polymer material. In construction with the other components (named hardening agent $\mathrm{K}_{2} \mathrm{~S}_{2} \mathrm{O}_{8}$ ), it will form the final mesh structure of high polymer by making the material produces rapid secondary crosslinking reaction[8-10].In order to develop better adhesive performance, nano MMT will be added to polymethylmethacrylate adhesives . By contrast test research of adding different proportion MMT nanoparticles and considering mechanics and economic performance, the test choice adding 3\% of nano MMT together with $1 \%, 2 \%, 3 \%, 4 \%, 5 \%$ five different hardening agent of polymethylmethacrylate to do adhesive performance testing. Specific material composition design is shown in Table 1.

Table 1 Two-component nano modified polymethylmethacrylate materials design

\begin{tabular}{cccc}
\hline Group number & MMA $(\mathrm{g})$ & Hardening agent & MMT $(\mathrm{g})$ \\
\hline 1 & 100 & 1 & 3 \\
2 & 100 & 2 & 3 \\
3 & 100 & 3 & 3 \\
4 & 100 & 4 & 3 \\
5 & 100 & 5 & 3 \\
\hline
\end{tabular}

\section{Test Method}

Bond strength of coating material before and after the nano modification is done by using universal testing machine to complete tensile test of two pieces of bond cement mortar, the test is shown in Fig. 5.

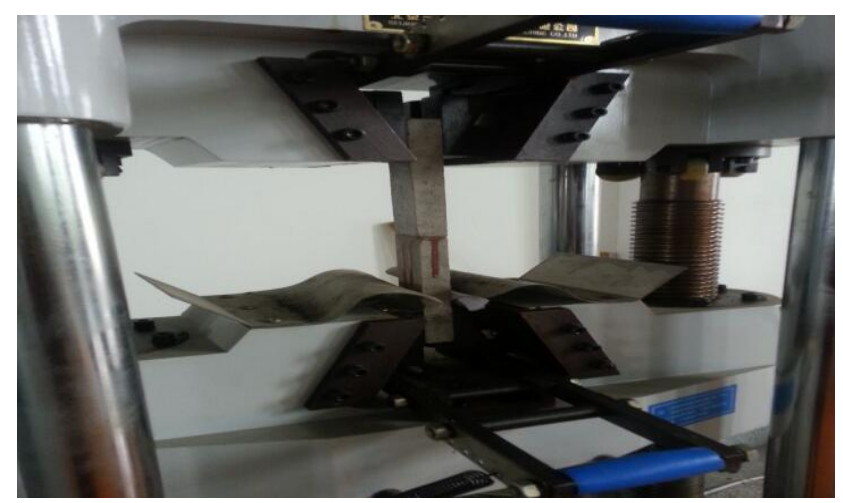

Fig.5 Tensile experiment figure 


\section{Results and Discussion}

Tensile experimental results of Polymethylmethacrylate with adding 3\% MMT and different Content of hardening agent are shown in Table 2 and Table 3.

Table 2 Tensile experiment results of polymethylmethacrylate

\begin{tabular}{cccccc}
\hline $\begin{array}{c}\text { Content of hardening } \\
\text { agent }(\%)\end{array}$ & 1 & 2 & 3 & 4 & 5 \\
\hline Force value $(\mathrm{KN})$ & 5.40 & 5.38 & 5.30 & 5.22 & 5.12 \\
Displacement $(\mathrm{mm})$ & 1.20 & 1.29 & 1.36 & 1.33 & 1.28 \\
\hline \multicolumn{5}{l}{ Table 3 Polymethylmethacrylate tensile experimental results by adding } & 3\% \\
\hline Content of hardening & 1 & 2 & 3 & 4 & 5 \\
agent $(\%)$ & & & & & \\
\hline Force value $(\mathrm{KN})$ & 6.11 & 5.98 & 5.78 & 5.70 & 6.04 \\
Displacement $(\mathrm{mm})$ & 1.25 & 1.33 & 1.23 & 1.25 & 1.33 \\
\hline
\end{tabular}

According to the Eq. (1).

$\mathrm{C}=1.8 \mathrm{QT} / 0.7$

QT - tensile strength (KN)

C - bond strength (Mpa)

Table 4 of Polymethylmethacrylate adhesive strength before and after adding 3\% nano MMT is calculated by Formula (1).

Table 4 PMMA adhesive strength before and after adding 3\% nano MMT

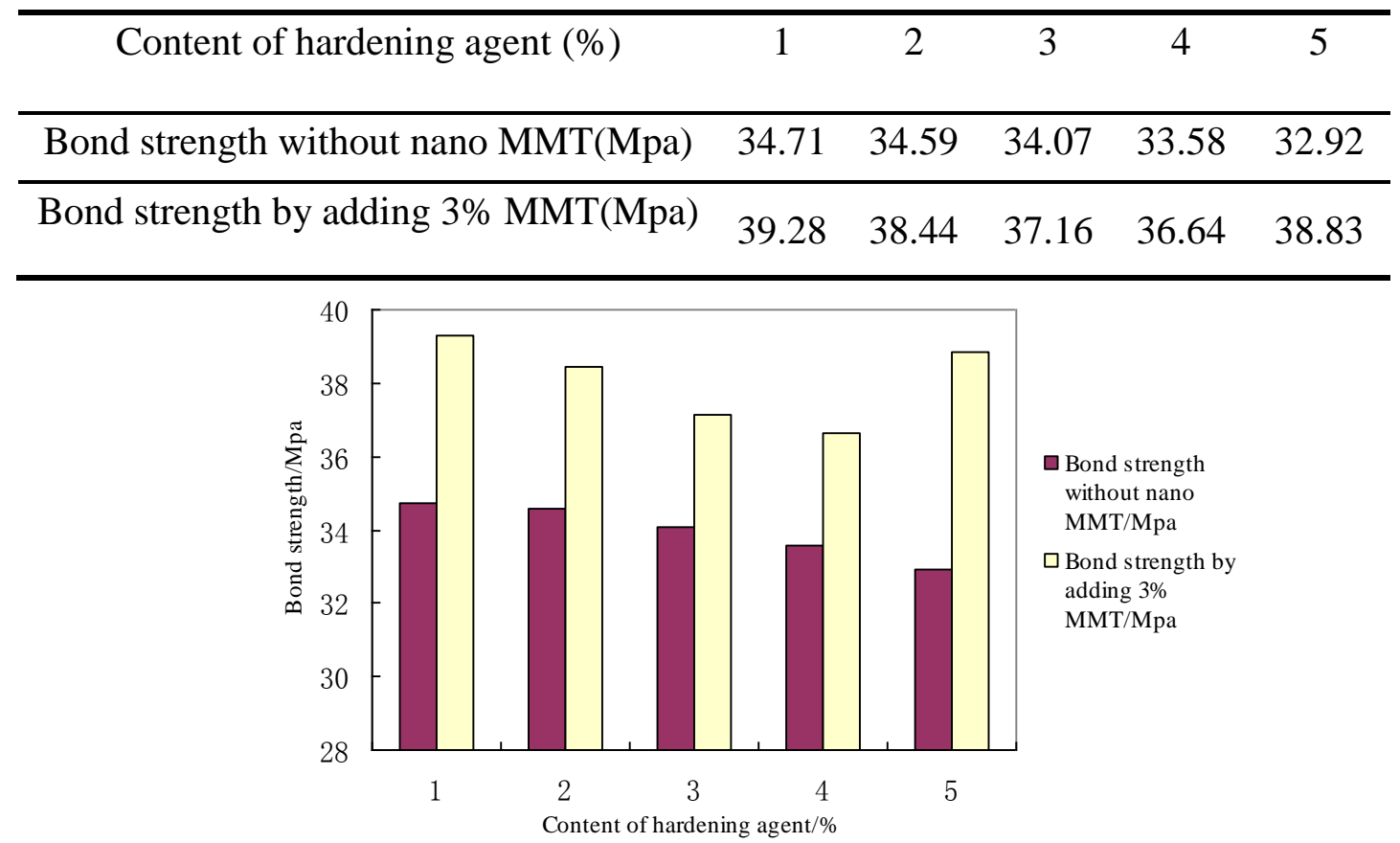

Fig.6 Adhesive strength histogram of PMMA and adding 3\% MMT PMMA 
By Table 4 and Fig.6, polymethylmethacrylate adhesive bond strength is between $30 \mathrm{MPa}$ and 35 $\mathrm{MPa}$. As a whole the bonding degree decreases with the increase of hardening agent. By adding $3 \%$ of MMT, polymethylmethacrylate adhesive strength is between $35 \mathrm{MPa}$ and $40 \mathrm{MPa}$. No matter how much content of hardening agent, the bond strength by adding 3\% nano MMT is bigger than the bond strength without adding nano MMT materials. The bond strength reduces colored anti-skid pavement threshing phenomenon and greatly improves colored anti-skid pavement durability.

\section{Conclusions}

Polymethylmethacrylate adhesives with nano MMT can significantly increase the bonding strength. By adding 3\% of nano MMT to polymethylmethacrylate, adhesive strength is between $35 \mathrm{MPa}$ and $40 \mathrm{MPa}$ which is significantly higher than that of polymethylmethacrylate adhesive bond strength $30 \mathrm{MPa}$ to $35 \mathrm{MPa}$. Hardening agent can reduce the hardening time and bonding degree decrease with the increase of hardening agent.

\section{Acknowledgement}

In this paper, the research was sponsored by the Project supported by the Natural Science Foundation of the Jiangsu Higher Education Institutions of China(Grant No. 15KJB580002), Huaian science and technology development project (Project No. HAGZ2014007), and program in Huaiyin institute of technology research funding for going abroad.

\section{References}

[1] Zhao An-ping, Thang Aiping. Color non-slip surface coating properties and applications [J]. Road construction machinery and construction mechanization, 2013, (02): 31-34.

[2] Lv Wei-min, Li li-han. Both at home and abroad the research and application of colored pavement [J]. Journal of Shanghai municipal engineering, 1998, (02): 53-55.

[3] Bellotti C, Bellotti F, Gloria AD. Developing a near infrared based night vision system[C].IEEE Intelligent Vehicles Symposium,2004:14-17.

[4] Gong Changsheng,Zhang Kesheng. New functional materials [M]. Beijing: chemical industry press, 2001.

[5] Zhang Shenglin, Zhao an-ping, Shang Aiping, Yu xue-mei .current situation and the development of colored antiskid pavement $[\mathrm{J}]$. Journal of . road construction machinery and construction mechanization, 2013, (02) : 26 -30.

[6] Wang Liangyan, Han Daojun, Chen Shizhou. Color pavement technology and development [J]. Journal of transportation science and technology and economic, 2009, 52 (02): 21-30.

[7]Chen Shiwei, Lu Xuchen, Zhang Zhimin. Preparation and characterization of poly (methyl methacrylate) reactive montmorillonite nanocomposites [J]. Polymer composites, 2016, 2396-2403

[8] Ma Zhong-nan .Research quality skid coatings and application technology [J] .Highway and Transportation Research: Application and Technology, 2012, (2): 89-92

[9] Luo Hai-bing. Colored pavement technical solutions and color non-slip surface design [J]. China Municipal Engineering, 2007, (2): 11-16. 
[10] Shao Qi, Li Aiguo, Ran Meng- Jiang. International Airport Highway colored pavement design and application [J] .Highway, 2009, (6): 193-196. 